via Halifax in $14 \frac{1}{3}$ days. She was equipped with steam engines driving paddle wheels, and her average speed was $8 \frac{1}{2}$ knots. Since then, the speed of the steamers has increased uniformly up to the present when it is 30 knots. The tonnage of the Britannia was 1,154 and her length was $207 \mathrm{ft}$. The tonnage of the Queen Mary is 80,773 and her length $1,020 \mathrm{ft}$. When it is realized that the former ship was equipped with engines barely equal to the power equipment of a modern trawler, our respect for the pioneers in sea transport is greatly increased. The horse-power of the Queen Mary is nearly 200,000 whilst that of the Britannia was 740. The author deals with the auxiliary plant which the Metropolitan-Vickers Co. supplied to the Queen Mary. These have chiefly to do with the winches and the ventilating system. There are six cargo winches, the same number of gangway winches and three baggage winches. These three types are all self-contained water-tight units. The ventilating system is naturally very extensive. There are no less than $\mathbf{4 0}$ miles of duct through which 118 million cubic feet of air are driven per hour.

\section{Mediterranean Unity and Diversity}

THE unity of the Mediterranean world in all geographical aspects, physical, climatic and vegetational, is a familiar conception to all geographers, and nowhere has the theme been more ably ex. pounded than in a lecture by Dr. G. Sarton on "The Unity and Diversity of the Mediterranean World" (Osiris, 2, Part 9). While he dwells on this unity, enhanced by relative enclosure, he points out also the effective channels by which the area is linked with the outer world, especially with the civilizations of the East in ancient times, and the diversity within the larger unity owing to enclosed seas and restricted area of high fertility. These ideas he expounds as a background for a study of Mediterranean civilization. Among many links between geographical conditions and human development, Dr. Sarton takes the myth of St. George. Everywhere in the Near East, Al-Khidr, the young or ever-living one, is venerated by Muslims as well as by Jews and Christians. The festivals of Al-Khidr, Elijah and St. George occur on the same day, April 23, which, irrespective of religion, is one of the important holidays. St. George or Al-Khidr is not simply an ever-living one but a giver of life, for he is the most powerful rain-bringer, and in the Mediterranean rain has a vital significance. His name is connected with the struggle against darkness, winter and drought. $\mathrm{He}$ is the recrudescence of spring and he symbolizes the struggle against evil and ignorance. Dr. Sarton suggests that if ever the historian of science should need a patron saint, he could not find a better one than Al-Khidr or St. George, the ever-living symbol of Mediterranean unity and diversity, of our culture and ideals, and of the everlasting struggle between truth and superstition.

\section{Forests of Trinidad and Tobago}

THE forests of Trinidad are not one of the least of its beauties, and a recent informative statement on them ("Forests and Forestry in Trinidad and Tobago". Govt. Printer, Trinidad, 1935) was drawn up by Mr. R. L. Brooks, the conservator of forests, for the British Empire Forestry Conference held in South Africa last year. The statement covers the whole field of forestry administration tracing the past history, geographical position, geology, climate and distribution of the forests in the Islands; and the botanical types of the forest growth. There is a small amount of private planting undertaken, but forestry activities are chiefly confined to the Department of Forestry. Co-operation exists between the Agricultural Society of Trinidad and Tobago and the Department. This Society publishes a quarterly record of its work in its Proceedings, but the chief scientific journal of Trinidad is Tropical Agriculture, the monthly journal of the Imperial College of Tropical Agriculture, in which forestry articles occasionally appear. The problems connected with forestry in its professional aspects are discussed in some detail by the conservator, Mr. Brooks, whose statement may be confidently recommended to those visiting Trinidad wishing for information on the Islands not available in the ordinary popular guide books. It suffers, as is the case with others submitted to the Empire Forestry Conference, in having been drawn up on a common prescribed schedule. A "Progress Report on Exotics" and a statement on "Timber Consumption and Marketing" were also drawn up for Trinidad and Tobago for the Empire Conference.

\section{The Lyre-bird in Victoria}

CONCERN has been expressed at the possibility of the extinction of the lyre-bird in Victoria, but F. Lewis, chief inspector of fisheries and game, points to the improvement which has taken place in public opinion, the more rigorous protection by law, and the fact that a great deal of the land inhabited by lyrebirds is rough and inaccessible (Victoria Naturalist, 53, 12 ; May 1936). $\mathrm{He}$ is of opinion that the future of the lyre-bird is assured, granted that public opinion in favour of protection continues to be educated in country districts as well as in the cities, and that a stop should be put to the clearing of lyre-bird gullies and the destruction wrought by bush-fires and the activities of egg-collectors. In another paper in the same journal (p. 3), R. T. Littlejohns states that no other Australian bird adheres so strongly to a definite area. In this case, the territory is two or three acres in extent, and for week after week, especially during the singing season, the place of any particular individual may be known exactly. It is seldom indeed that a bird is to be found outside its own area.

\section{Allotments as an Amenity Asset}

Although few will question the value of allotments, their frequent unsightliness is one of the chief reasons why there is so little public support for including them in town-planning schemes or otherwise making their tenure secure. Useful work has already been done by the National Allotments 